\title{
Physiological, Hemato-biochemical and Urine Parameters Alterations in Lower Urinary Tract Affections in Dogs under Various Therapeutics Management
}

\author{
J. J. Parmar*, P. V. Parikh, P. B. Dabhi, A. S. Parmar and KavitaKurup \\ College of Veterinary Science and Animal Husbandry, Anand Agricultural University, \\ Anand, India \\ *Corresponding author
}

\section{A B S T R A C T}

\section{Keywords}

Lower Urinary

Tract Affections in

Dogs, Therapeutics

Management

Article Info

Accepted:

15 December 2020

Available Online:

10 January 2021
A total of 55 dogs with the lower urinary tract affections were selected during September2017 to July-2019, comprising dogs having urolithiasis under Group 1A (medicinal dissolution with Ammonium Chloride, $\mathrm{n}=9$ ), Group 1B (medicinal dissolution with $\mathrm{Di}$ Sodium Hydrogen Citrate, $\mathrm{n}=10)$, Group 1C ( $\mathrm{n}=25$; cystitis, 17; mass in bladder, 8$)$. The dogs under Group $2(\mathrm{n}=10$, large uroliths; $\mathrm{n}=1$, lodged catheter in bladder) and Group 3 $(\mathrm{n}=6$, cases failed to medicinal dissolution under Group 1A $(\mathrm{n}=2)$ and Group 1B $(\mathrm{n}=4))$ were subjected to surgical management. The mean rectal temperatures were normal with non-significant variation, except in the dogs with cystitis (Group 1C) had low ( $\mathrm{p}<0.05)$ one. The mean respiration rates were normal, varying non-significantly, except the in the dogs with larger calculi (Group 2) managed surgically. The mean pulse rates were also normal varying non-significantly. The mean $\mathrm{Hb}$, TLC and DLC, ESR, PCV, blood sugar, SGPT, serum creatinine and BUN were normal varying non-significantly on day ' 0 ', 10 and 20 for all the dogs covered under various treatment groups. Whereas mean platelets count significantly increased in the dogs having cystitis (Group 1C). Dogs with urolithiasis had absence of crystals in 68.97 per cent (20) cases, whereas struvite and calcium oxalate crystals were recorded in 27.58 (08) and 3.44 (1) per cent cases, respectively. The dogs having cystitis had leucocytes and intact RBCs in all the urine samples, with epithelial cells in few cases. The dogs with cystitis and neoplasia (Group 1C), and larger calculi (Group 2) had significant reduction in the mean $\mathrm{RBC} / \mathrm{hpf}$ in urine. The mean urine protein and $\mathrm{WBC} / \mathrm{hpf}$ levels on days ' 0 ', 10 and 20 in dogs varied non-significantly, except the in the dogs having cystitis (Group 1C) and larger calculi (Group 2). The mean urine bilirubin, urobilinogen, urine ketone levels, $\mathrm{pH}$ and specific gravity varied non-significantly. None of the dogs revealed glycosuria and nitritemia.

\section{Introduction}

The lower urinary tract disorders are common in small animal practice with multiple factors which contribute to complicate recurrent urinary infection. A clinical and common diagnostic examinations such as blood count test, physic-chemical examination of urine 
and urine sediment, microbiological examination of urine, X-ray and ultrasound examinations of the abdominal cavity do not always allow an ultimate diagnosis (Cannizzo et al., 2001). Urinalysis is a remarkable inexpensive tool for the diagnosis and management of numerous urinary tract abnormalities, also act as a tool that can reveal many of the diseases that could go unnoticed and undiagnosed because they generally do not produce striking signs or symptoms. Observing the colour, transparency, microscopic and chemical characteristics of urine likely to identify majority of the lower urinary tract disorders in domestic animals and it is still a much neglected facet in veterinary medicine (Parrah et al., 2013). The published data pertaining to the physiological, hemato-biochemical and urinalysis parameters from dogs affected with various affections of lower urinary tract is very merge. This research paper presents a physiological, hemato-biochemical and urinalysis findings and changes during various therapeutic management in dogs affected with various lower urinary tract disorders.

\section{Materials and Methods}

The present study was undertaken in 55 dogs presented with various affections of lower urinary tract at the Department of Veterinary Surgery and Radiology, College of Veterinary Science and Animal Husbandry, Anand Agricultural University, Anand from September 2017 to July 2019 for detailed investigation, medicinal and surgical management.

The dogs having urolithiasis with urine $\mathrm{pH}$ to be ranging from 7.5 to 8.5 (Group $1 \mathrm{~A}, \mathrm{n}=9$ ) and subjected to dissolution using Ammonium Chloride @ $5 \mathrm{mg} / \mathrm{kg}$ body weight orally and urine $\mathrm{pH}$ to be ranging from 6.5 to 7.0 (Group 1B, $\mathrm{n}=10$ ) were subjected to therapeutic dissolution using Di Sodium Hydrogen Citrate @ $0.03 \mathrm{mg} / \mathrm{kg}$ body weight orally for 60 days. In group $1 \mathrm{C}(\mathrm{n}=25)$ cases with cystitis $(n=17)$ treated with antibiotics based on urine culture and antibiotics sensitivity test and mass in urinary bladder $(n=8)$ treated with immunotherapy using BCG vaccine. In group 2 ten cases had large uroliths and one case of lodge catheter un bladder surgical management was done while in group 3 six cases which were not responded to medicinal dissolution protocols of group 1A and 1B were included in this group and subjected for surgical management.

In all the cases the Rectal Temperature $\left({ }^{\circ} \mathrm{F}\right)$, Pulse and Respiration Rates per minutes were recorded on day (' 0 '), 10 and 20 of the medicinal or surgical treatment. Thehematobiochemicalparameters like Haemoglobin (g/dl), Total Leukocyte Count $\left(\times 10^{3}\right)$, Differential Leukocyte Count (DLC), Platelets $\quad\left(10^{5} / \mathrm{cmm}\right), \quad$ Erythrocyte Sedimentation Rate (mm/hour), Packed Cell Volume (\%), Blood Glucose (mg/dl), Serum Glutamic Pyruvic Transaminase (U/L), Serum Creatinine $(\mathrm{mg} / \mathrm{dl})$, Blood Urea Nitrogen $(\mathrm{mg} / \mathrm{dl})$ were measured on day (' 0 '), 10 and 20 post treatment. The urine samples from all the groups were analysed for macroscopic, microscopic examinations from dogs having urolithiasis and cystitis and also analysed for presence of blood as well as multiple parameters like bilirubin, urobilinogen, ketones, protein, nitrite, glucose, $\mathrm{pH}$, specific gravity and leukocytes using Uriscan Multistrip. The changes in the colour of strip were compared with standard colour chart. The numerical measurements were recorded according to change in colour of strips.

The data pertaining to different parameters covered under the study were subjected to statistical analysis by Completely Randomized Design. The effects of the different treatments on various hemato- 
biochemical and urine parameters were compared between the intervals.

\section{Results and Discussion}

\section{Physiological parameters}

The mean rectal temperature was found within the normal values, varying nonsignificantly, except in the dogs under Group 1C having cystitis with significantly lower rectal temperature (Table 1). The mean respiration rate was found within the normal values, varying non-significantly, except the in the dogs under Group 2 subjected for surgical management with significantly higher respiration rate was noted (Table 2). The mean pulse found in the present study was within the normal values, varying nonsignificantly on day (' 0 '), 10 and 20 post treatment in all cases. Sharma (2001) reported normal rectal temperature, elevated respiration and pulse rates. While higher rectal temperature, respiration and pulse rates were recorded by Kamble et al., (2011) whereas Gupta (2014) in dogs having urolithiasis and normal rectal temperature in dogs having growth in bladder, elevated respiration rates in dogs with cystitis, growth in urinary bladder and normal pulse rate in dogs suffered from urolithiasis, cystitis, growth and polyp in urinary bladder.

\section{Hemato-biochemical Parameters}

The mean haemoglobin (g/dl), TLC, Neutrophils, Lymphocytes, Eosinophils, Monocytes, ESR, PCV, blood glucose, SGPT, serum creatinine and blood urea nitrogen were found within the normal values, varying non-significantly in all dogs on day (' 0 '), 10 and 20 post treatment in all cases.

The findings of the haemoglobin level in present study are in agreement with findings of Sran (2010), Pal (2015), Taskande (2015) and Pandurangrao (2017). However, in contrary to the present findings, comparatively lower haemoglobin concentrations were recorded by Kamble et al., (2011), Madhu et al., (2013) and Gohil (2016) in dogs. Sahoo et al., (2016) reported anaemia in six year Spitz dog having lodged catheter in bladder. The mean haemoglobin concentrations found in the present study in dogs with cystitis were also within the normal limit but were comparatively lower than those of dogs with urolithiasis. The findings of the present study are in agreement with the observations reported by Roopali et al., (2018), Sarma and Kalita (2019) in dogs. The mean haemoglobin concentrations found in the present study in dogs with neoplasia in bladder were also within the normal limit but were comparatively lower than those of dogs with urolithiasis. This finding is in agreement with the findings of Manjunatha et al., (2016).

The mean neutrophils and lymphocyte counts were within the normal values, varying nonsignificantly. However, in contrary to the findings of the present study, neutrophilia and increase lymphocytes reported by Sarma and Kalita (2019). No comparable reports could be located on the same line for the dogs having neoplasia in bladder. However, in contrary to the present findings, lymphopenia and thromocytopenia reported by Brunet al., (2008) and Roopali et al., (2018) in dogs. No comparable reports could be located on the same line for mean lymphocyte (\%) levels in dogs with cystitis.

The mean eosinophils, monocytes count. ESR and PCV within the normal values, varying non-significantly on day (' 0 '), 10 and 20 post treatment in all cases. However, in contrary to the present findings, lower per cent eosinophils, monocyte count and PCV was reported by Brun et al., (2008) in dogs with urolihtiais and Roopali et al., (2018) in dogs with cystitis. No comparable reports could be 
located for comparison of mean values of eosinophills and monocytes (\%) in the dogs having masses in the bladder. Mukherjee et al., (2014) reported normal ESR in dogs affected with urolithiasis and cystitis. No any comparable research findings on the same line could be located while screening the literature for dogs suffering from mass in bladder. The PCV value (\%) was found to be within the normal range in dogs having cystitis and mass in bladder in the present study.

Table.1 Mean $( \pm \mathrm{SE})$ rectal temperature $\left({ }^{\circ} \mathrm{F}\right)$ in dogs under different treatment groups

\begin{tabular}{|c|c|c|c|c|c|c|}
\hline \multirow[b]{2}{*}{ Period } & \multicolumn{4}{|c|}{ Therapeutic Management Groups } & \multicolumn{2}{|c|}{$\begin{array}{c}\text { Therapeutic and/or } \\
\text { Surgical Management } \\
\text { Groups }\end{array}$} \\
\hline & $\begin{array}{c}1 \mathrm{~A} \\
\text { (Ammonium } \\
\text { Chloride) } \\
(\mathrm{n}=7)\end{array}$ & $\begin{array}{c}\text { 1B } \\
\text { (Di } \\
\text { Sodium } \\
\text { Hydrogen } \\
\text { Citrate) } \\
(\mathrm{n}=6)\end{array}$ & $\begin{array}{c}1 \mathrm{C} \\
\text { (Cystitis) } \\
(\mathrm{n}=17)\end{array}$ & $\begin{array}{c}1 \mathrm{C} \\
\text { (Mass in bladder) } \\
\text { Immunotherapy }(\mathrm{n}=8)\end{array}$ & $\begin{array}{c}2 \\
\text { (Surgery) } \\
(\mathrm{n}=11)\end{array}$ & $\begin{array}{c}3 \\
\text { (Medicine }+ \\
\text { Surgery) }(\mathrm{n}=6)\end{array}$ \\
\hline Day 0 & $101.8 \pm 0.39$ & $102.5 \pm 0.38$ & $101.8 \pm 0.27$ & $101.8 \pm 0.20$ & $101.5 \pm 0.19$ & $102.1 \pm 0.28$ \\
\hline Day 10 & $101.8 \pm 0.28$ & $101.9 \pm 0.33$ & $101.4 \pm 0.24$ & $102.0 \pm 0.19$ & $102.1 \pm 0.36$ & $101.9 \pm 0.50$ \\
\hline Day 20 & $101.3 \pm 0.25$ & $101.7 \pm 0.22$ & $100.5 \pm 0.27$ & $101.6 \pm 0.11$ & $101.0 \pm 0.29$ & $101.1 \pm 0.24$ \\
\hline Sem & 0.31 & 0.32 & 0.27 & 0.17 & 0.29 & 0.36 \\
\hline CD & NS & NS & 0.764 & NS & NS & NS \\
\hline CV\% & 0.82 & 0.78 & 1.09 & 0.49 & 0.95 & 0.87 \\
\hline
\end{tabular}

Table.2 Mean $( \pm \mathrm{SE})$ respiration rate (per min) in dogs under different treatment groups

\begin{tabular}{|c|c|c|c|c|c|c|}
\hline \multirow[b]{2}{*}{ Period } & \multicolumn{4}{|c|}{ Therapeutic Management Groups } & \multicolumn{2}{|c|}{$\begin{array}{l}\text { Therapeutic and/or } \\
\text { Surgical Management } \\
\text { Groups }\end{array}$} \\
\hline & $\begin{array}{c}1 \mathrm{~A} \\
\text { (Ammonium } \\
\text { Chloride) } \\
(\mathrm{n}=7)\end{array}$ & $\begin{array}{c}\text { 1B } \\
\text { (Di Sodium } \\
\text { Hydrogen } \\
\text { Citrate) } \\
(\mathrm{n}=6)\end{array}$ & $\begin{array}{c}1 \mathrm{C} \\
(\text { Cystitis }) \\
(\mathrm{n}=17)\end{array}$ & $\begin{array}{c}1 \mathrm{C} \\
\text { (Mass in } \\
\text { bladder) } \\
\text { Immunotherapy } \\
(\mathrm{n}=8)\end{array}$ & $\begin{array}{c}2 \\
(\text { Surgery) } \\
(\mathrm{n}=11)\end{array}$ & $\begin{array}{c}3 \\
\text { (Medicine }+ \\
\text { Surgery) } \\
(\mathrm{n}=6)\end{array}$ \\
\hline Day 0 & $24.42 \pm 1.88$ & $23.50 \pm 2.36$ & $22.88 \pm 0.95$ & $22.50 \pm 1.48$ & $22.54 \pm 0.67$ & $20.33 \pm 1.72$ \\
\hline Day 10 & $26.14 \pm 1.63$ & $25.50 \pm 2.09$ & $24.35 \pm 1.23$ & $23.25 \pm 1.39$ & $24.45 \pm 0.60$ & $21.66 \pm 1.28$ \\
\hline Day 20 & $28.28 \pm 1.61$ & $25.16 \pm 2.07$ & $25.17 \pm 1.01$ & $24.62 \pm 1.43$ & $25.36 \pm 0.86$ & $22.50 \pm 0.99$ \\
\hline Sem & 1.71 & 2.18 & 1.07 & 1.44 & 0.72 & 1.36 \\
\hline CD & NS & NS & NS & NS & 2.09 & NS \\
\hline CV\% & 17.29 & 21.60 & 18.35 & 17.38 & 9.98 & 15.57 \\
\hline
\end{tabular}


Table.3 Mean $( \pm \mathrm{SE})$ platelets $\left(10^{5} / \mathrm{cmm}\right)$ levels in dogs covered under different treatment groups

\begin{tabular}{|c|c|c|c|c|c|c|}
\hline & \multicolumn{5}{|c|}{ Therapeutic Management Groups } & $\begin{array}{c}\text { Therapeutic and/or Surgical } \\
\text { Management Groups }\end{array}$ \\
\hline Period & $\begin{array}{c}\text { 1A (Ammonium } \\
\text { Chloride) }(\mathrm{n}=7)\end{array}$ & $\begin{array}{c}1 \mathrm{~B} \\
\text { (Di Sodium } \\
\text { Hydrogen } \\
\text { Citrate) }(\mathrm{n}=6)\end{array}$ & $\begin{array}{c}1 \mathrm{C} \\
(\text { Cystitis }) \\
(\mathrm{n}=17)\end{array}$ & $\begin{array}{c}1 \mathrm{C} \\
\text { (Mass in bladder) } \\
\text { Immunotherapy } \\
(\mathrm{n}=8)\end{array}$ & $\begin{array}{c}2 \\
\text { (Surgery) } \\
(\mathrm{n}=11)\end{array}$ & $\begin{array}{c}\text { (Medicine }+ \\
\text { Surgery) } \\
(\mathrm{n}=6)\end{array}$ \\
\hline Day 0 & $2.03 \pm 0.07$ & $1.56 \pm 0.28$ & $1.91 \pm 0.18$ & $1.78 \pm 0.42$ & $2.58 \pm 0.21$ & $2.38 \pm 0.19$ \\
\hline Day 10 & $1.93 \pm 0.15$ & $2.37 \pm 0.39$ & $2.26 \pm 0.17$ & $1.84 \pm 0.18$ & $2.56 \pm 0.21$ & $2.42 \pm 0.30$ \\
\hline Day 20 & $1.98 \pm 0.21$ & $2.71 \pm 0.33$ & $2.83 \pm 0.19$ & $2.17 \pm 0.21$ & $3.98 \pm 0.16$ & $2.51 \pm 0.27$ \\
\hline Sem & 0.15 & 0.34 & 0.18 & 0.29 & 0.19 & 0.26 \\
\hline CD & $\mathrm{NS}$ & $\mathrm{NS}$ & 0.52 & $\mathrm{NS}$ & $\mathrm{NS}$ & $\mathrm{NS}$ \\
\hline CV\% & 21.04 & 37.51 & 32.2 & 42.96 & 23.81 & 26.53 \\
\hline
\end{tabular}

Table.4 Mean $( \pm \mathrm{SE})$ Blood $(\mathrm{RBC} / \mathrm{hpf})$ in urine of dogs covered under different treatment groups

\begin{tabular}{|c|c|c|c|c|c|c|}
\hline \multirow[b]{2}{*}{ Period } & \multicolumn{4}{|c|}{ Therapeutic Management Groups } & \multicolumn{2}{|c|}{$\begin{array}{c}\text { Therapeutic and/or Surgical } \\
\text { Management Groups }\end{array}$} \\
\hline & $\begin{array}{l}\text { 1A (Ammonium } \\
\text { Chloride) }(\mathrm{n}=7)\end{array}$ & $\begin{array}{c}\text { 1B } \\
\text { (Di Sodium } \\
\text { Hydrogen Citrate) } \\
(\mathrm{n}=6)\end{array}$ & $\begin{array}{c}1 \mathrm{C} \\
(\text { Cystitis }) \\
(\mathrm{n}=17)\end{array}$ & $\begin{array}{c}1 \mathrm{C} \\
\text { (Mass in } \\
\text { bladder) } \\
\text { Immunotherapy } \\
(\mathrm{n}=8)\end{array}$ & $\begin{array}{c}2 \\
(\text { Surgery) } \\
(\mathrm{n}=11)\end{array}$ & $\begin{array}{c}3 \\
\text { (Medicine }+ \\
\text { Surgery) }(n=6)\end{array}$ \\
\hline Day 0 & $24.28 \pm 9.22$ & $60.00 \pm 39.15$ & $14.11 \pm 4.29$ & $143.75 \pm 45.74$ & $56.36 \pm 29.42$ & $50.00 \pm 40.82$ \\
\hline Day 10 & $14.28 \pm 9.22$ & $51.66 \pm 40.44$ & $1.17 \pm 0.80$ & 18.759 .14 & Nil & Nil \\
\hline Day 20 & Nil & $08.33 \pm 8.33$ & Nil & $1.25 \pm 1.25$ & Nil & Nil \\
\hline Sem & 7.52 & 32.85 & 2.52 & 26.94 & 16.99 & 23.57 \\
\hline CD & NS & NS & 7.175 & 79.256 & 49.063 & NS \\
\hline CV\% & 154.93 & 201.21 & 203.93 & 139.61 & 299.91 & 346.41 \\
\hline \multicolumn{7}{|c|}{ Figures in the parenthesis indicate number of animals } \\
\hline
\end{tabular}

Table.5 Mean $( \pm \mathrm{SE})$ protein $(\mathrm{mg} / \mathrm{dl})$ in urine of dogs covered under different treatment groups

\begin{tabular}{|c|c|c|c|c|c|c|}
\hline \multirow[b]{2}{*}{ Period } & \multicolumn{4}{|c|}{ Therapeutic Management Groups } & \multicolumn{2}{|c|}{$\begin{array}{c}\text { Therapeutic and/or Surgical } \\
\text { Management Groups }\end{array}$} \\
\hline & $\begin{array}{c}1 \mathrm{~A} \\
\text { (Ammonium } \\
\text { Chloride) }(\mathrm{n}=7)\end{array}$ & $\begin{array}{c}\text { 1B } \\
\text { (Di Sodium } \\
\text { Hydrogen Citrate) } \\
(\mathrm{n}=6)\end{array}$ & $\begin{array}{c}1 \mathrm{C} \\
(\mathrm{Cystitis}) \\
(\mathrm{n}=17)\end{array}$ & $\begin{array}{c}1 \mathrm{C} \\
\text { (Mass in } \\
\text { bladder) } \\
\text { Immunotherapy } \\
(\mathrm{n}=8)\end{array}$ & $\begin{array}{c}2 \\
\text { (Surgery) } \\
(\mathrm{n}=11)\end{array}$ & $\begin{array}{c}3 \\
\text { (Medicine }+ \\
\text { Surgery) }(n=6)\end{array}$ \\
\hline Day 0 & $208.57 \pm 137.77$ & $58.33 \pm 48.53$ & $\begin{array}{l}127.05 \pm \\
29.54\end{array}$ & $300 \pm 156.98$ & $\begin{array}{c}309.09 \pm \\
136.48\end{array}$ & $181.66 \pm 163.77$ \\
\hline Day 10 & $161.42 \pm 140.44$ & $186.66 \pm 163.41$ & $38.23 \pm 18.94$ & $176.25 \pm 123.31$ & $00.90 \pm 0.90$ & $201.66 \pm 160.83$ \\
\hline Day 20 & $51.42 \pm 41.77$ & $51.66 \pm 49.69$ & $07.64 \pm 6.03$ & $375 \pm 182.98$ & $00.90 \pm 0.90$ & $30.00 \pm 16.32$ \\
\hline Sem & 116.12 & 102.5 & 20.55 & 156.34 & 78.80 & 132.86 \\
\hline CD & NS & NS & 58.504 & NS & 227.567 & NS \\
\hline CV\% & 218.70 & 253.93 & 147.04 & 155.84 & 252.19 & 236.21 \\
\hline \multicolumn{7}{|c|}{ Figures in the parenthesis indicate number of animals } \\
\hline
\end{tabular}


Table.6 Mean $( \pm \mathrm{SE})$ leucocyte $(\mathrm{WBC} / \mathrm{hpf})$ in urine of dogs covered under different treatment groups

\begin{tabular}{|c|c|c|c|c|c|c|}
\hline \multirow[b]{2}{*}{ Period } & \multicolumn{4}{|c|}{ Therapeutic Management Groups } & \multicolumn{2}{|c|}{$\begin{array}{c}\text { Therapeutic and/or Surgical } \\
\text { Management Groups }\end{array}$} \\
\hline & $\begin{array}{l}\text { 1A (Ammonium } \\
\text { Chloride) }(\mathrm{n}=7)\end{array}$ & $\begin{array}{c}\text { 1B } \\
\text { (Di Sodium } \\
\text { Hydrogen } \\
\text { Citrate) } \\
(\mathrm{n}=6)\end{array}$ & $\begin{array}{c}1 \mathrm{C} \\
\text { (Cystitis) } \\
(\mathrm{n}=17)\end{array}$ & $\begin{array}{c}1 \mathrm{C} \\
\text { (Mass in } \\
\text { bladder) } \\
\text { Immunotherapy } \\
(\mathrm{n}=8)\end{array}$ & $\begin{array}{c}2 \\
(\text { Surgery) } \\
(\mathrm{n}=11)\end{array}$ & $\begin{array}{c}3 \\
\text { (Medicine }+ \\
\text { Surgery) }(n=6)\end{array}$ \\
\hline Day 0 & $96.42 \pm 68.44$ & $100.00 \pm 80.88$ & $47.05 \pm 8.54$ & $143.75 \pm 78.59$ & $143.18 \pm 69.42$ & $20.83 \pm 11.93$ \\
\hline Day 10 & $3.57 \pm 3.57$ & $187.50 \pm 99.94$ & $13.23 \pm 7.14$ & $134.37 \pm 80.30$ & - & $100.00 \pm 80.88$ \\
\hline Day 20 & $10.71 \pm 10.71$ & $95.83 \pm 81.75$ & - & $134.37 \pm 80.30$ & - & $100.00 \pm 80.88$ \\
\hline Sem & 40.05 & 87.96 & 6.43 & 79.74 & 40.08 & 66.39 \\
\hline CD & NS & NS & 18.301 & NS & 115.74 & NS \\
\hline CV\% & 287.15 & 168.63 & 131.93 & 164.03 & 278.52 & 220.94 \\
\hline \multicolumn{7}{|c|}{ Figures in the parenthesis indicate number of animals } \\
\hline
\end{tabular}

Table.7 Mean $( \pm \mathrm{SE}) \mathrm{pH}$ in urine of dogs covered under different treatment groups

\begin{tabular}{|c|c|c|c|c|c|c|}
\hline \multirow[b]{2}{*}{ Period } & \multicolumn{4}{|c|}{ Therapeutic Management Groups } & \multicolumn{2}{|c|}{$\begin{array}{c}\text { Therapeutic and/or } \\
\text { Surgical Management } \\
\text { Groups }\end{array}$} \\
\hline & $\begin{array}{l}\text { 1A (Ammonium } \\
\text { Chloride) }(n=7)\end{array}$ & $\begin{array}{c}1 \mathrm{~B} \\
\text { (Di Sodium } \\
\text { Hydrogen } \\
\text { Citrate) }(\mathrm{n}=6)\end{array}$ & $\begin{array}{c}1 \mathrm{C} \\
(\mathrm{Cystitis}) \\
(\mathrm{n}=17)\end{array}$ & $\begin{array}{c}1 \mathrm{C} \\
\text { (Mass in bladder) } \\
\text { Immunotherapy } \\
(\mathrm{n}=8)\end{array}$ & $\begin{array}{c}2 \\
(\text { Surgery }) \\
(\mathrm{n}=11)\end{array}$ & $\begin{array}{c}3 \\
\text { (Medicine }+ \\
\text { Surgery) } \\
(\mathrm{n}=6)\end{array}$ \\
\hline Day 0 & $7.64 \pm 0.09$ & $6.78 \pm 0.10$ & $7.21 \pm 0.27$ & $6.76 \pm 0.31$ & $6.08 \pm 0.22$ & $7.45 \pm 0.16$ \\
\hline Day 10 & $6.91 \pm 0.12$ & $6.95 \pm 0.39$ & $7.21 \pm 0.24$ & $6.76 \pm 0.36$ & $6.33 \pm 0.19$ & $7.13 \pm 0.21$ \\
\hline Day 20 & $7.34 \pm 0.23$ & $6.35 \pm 0.35$ & $7.32 \pm 0.19$ & 6.950 .34 & $6.76 \pm 0.13$ & $6.93 \pm 0.24$ \\
\hline Sem & 0.16 & 0.31 & 0.23 & 0.34 & 0.19 & 0.21 \\
\hline CD & 0.48 & NS & NS & NS & NS & NS \\
\hline CV\% & 5.90 & 11.37 & 13.57 & 14.24 & 9.83 & 7.27 \\
\hline \multicolumn{7}{|c|}{ Figures in the parenthesis indicate number of animals } \\
\hline
\end{tabular}

Fig.1 Struvite Crystals

Fig.2 Calcium Oxalate crystals
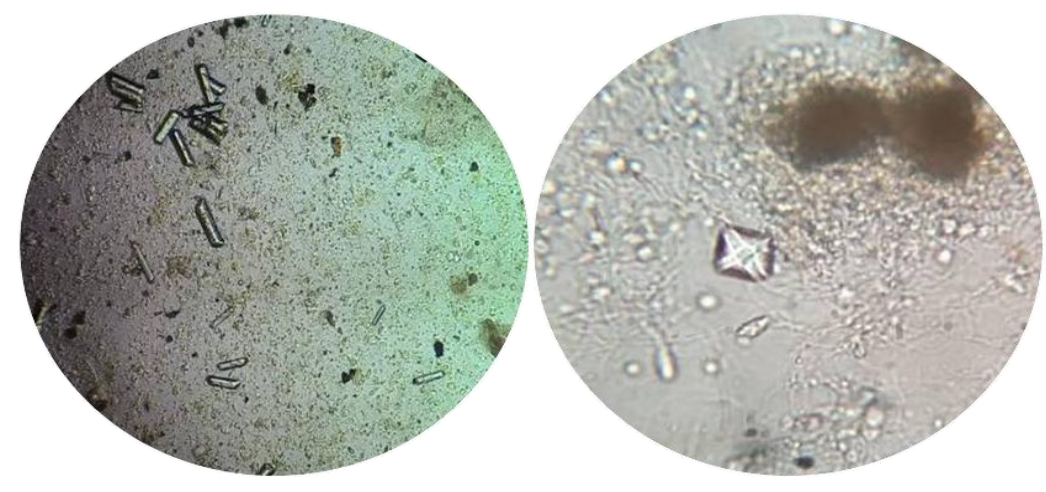
Fig.3 Presence of pus cells

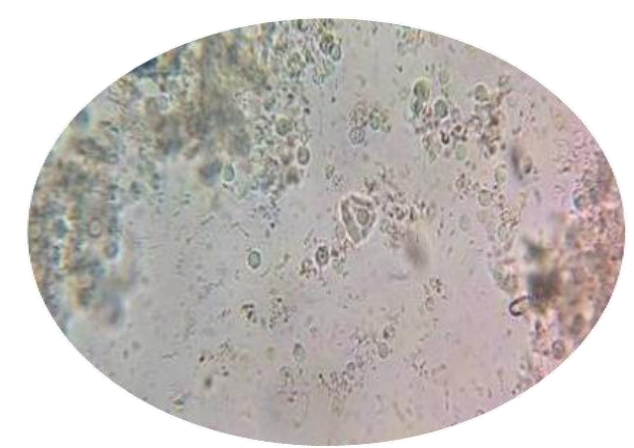

The mean platelets $\left(10^{5} / \mathrm{cmm}\right)$ levels found in the present study were within the normal values, varying non-significantly, except a significantly increased platelets count in the dogs having cystitis covered under Group 1C (Table 3). The mean platelets counts were within the normal limits in dogs covered under Group 1C having cystitis and neoplasia of urinary bladder in the present study. However, in contrary to the present findings, thrombocytopenia was reported by Brunet al., (2008) and Synghal et al., (2016) in dogs with urolithiasis. The mean platelets counts were within the normal limits in dogs covered under Group $1 \mathrm{C}$ having cystitis and neoplasia of urinary bladder in the present study. However, in contrary to the present findings, comparatively lower platelet count was reported by Roopali et al., (2018) in dogs and comparatively higher platelets count was reported by Caswell (2011) in dogs.

The mean blood glucose (mg/dl) levels recorded for the dogs covered under present study were within the normal physiological limits, varying non-significantly. However, in contrary to the present findings the mean blood glucose level below the normal limit was reported by Sharma et al., (2005) in dogs with urolithiasis. However, no comparable findings for sugar could be traced out for the cystitis and masses in the bladder in dogs while screening the literature.
The mean serum glutamic pyruvic acid (U/L) levels recorded for the dogs covered under present study on day ('0'), 10 and 20 were within the normal physiological limits, varying non-significantly. However, in contrary to the present findings comparatively higher levels of SGPT were reported by Singh et al., (2012) and Madhu et al., (2013) in dogs with urolithiasis. Sahoo et al., (2016) reported increased SGPT in six year spitz dog having lodged catheter in bladder. The mean level of SGPT in dogs covered under Group1C in the present study having cystitis and neoplasia of urinary bladder was found to be within the normal range. In comparison to the present findings, the higher SGPT levels were reported by Manjunatha et al., (2016) and Sahoo et al., (2016) in dogs.

In the present study the mean serum creatinine and BUN level was found to be within normal range in dogs having cystitis and neoplasia of bladder. The findings of the present study are supported by the findings of Manjunatha et al., (2016), Roopali et al., (2018), and Sarma and Kalita (2019) in dogs.Saharan et al., (2019) reported elevated creatinine and urea nitrogen levels in a nine year old female had urinary bladder leiomyoma. This findings are in agreement with the findings of Sarma and Kalita (2019). The mean pre-treatment serum creatinine $(\mathrm{mg} / \mathrm{dl})$ levels in dogs having neoplasia of urinary bladder was found to be higher than 
the normal limit which came to the normal levels after therapeutic management. The trend of decline in mean serum creatinine levels observed in the dogs having urolithiasis during the course of treatment is indicative of improvement in the urinary health status of dogs.

The dogs having urolithiasis covered under in Group 1A, macroscopic physical examinations of seven urine samples revealed dark reddish and reddish colour of urine in three dogs (42.86\%; each) for both and yellow colour in one dogs $(14.29 \%)$ on day 0 , while on day 10 dark reddish coloured urine was observed in a dog (14.29\%), reddish colour in two dogs $(28.57 \%)$ and yellow colour in four dogs $(57.14 \%)$. On day 20 reddish colour observed in two dogs $(28.57$ $\%)$ while in remaining five dogs $(71.43 \%)$ yellow colour recorded. Among the dogs studied for turbidity of urine on day 0 under in Group 1A, six dogs $(85.71 \%)$ were having turbid urine and clear urine in one dog (14.29 $\%$ ), while on day 10 the turbidity of urine was observed in four dogs $(57.14 \%)$ and three dogs $(42.86 \%)$ had clear urine. On day 20, only two $(28.57 \%)$ dogs had turbid urine whereas five $(71.43 \%)$ dogs had clear urine in five dogs.

\section{Urinalysis}

\section{Macroscopic examinations of urine}

The dogs having urolithiasis covered under in Group 1A, macroscopic physical examinations of seven urine samples revealed dark reddish and reddish colour of urine in three dogs (42.86\%; each) for both and yellow colour in one dogs $(14.29 \%)$ on day ('0'), while on day 10 dark reddish coloured urine was observed in a dog (14.29 \%), reddish colour in two dogs $(28.57 \%)$ and yellow colour in four dogs $(57.14 \%)$. On day 20 reddish colour observed in two dogs
(28.57\%) while in remaining five dogs $(71.43$ $\%)$ yellow colour recorded. Among the dogs studied for turbidity of urine on day 0 under in Group 1A, six dogs $(85.71 \%)$ were having turbid urine and clear urine in one dog (14.29 $\%$ ), while on day 10 the turbidity of urine was observed in four dogs $(57.14 \%)$ and three dogs $(42.86 \%)$ had clear urine. On day 20 , only two (28.57\%) dogs had turbid urine whereas five $(71.43 \%)$ dogs had clear urine in five dogs.

The dogs having urolithiasis covered under Group 1B, macroscopic physical examination of six urine samples on day ('0') revealed dark reddish urine in three dogs $(50.00 \%)$, reddish urine in two dogs $(33.33 \%)$ and yellow coloured urine in one dog $(16.67 \%)$. On day 10 reddish urine was observed in three dogs $(50.00 \%)$ and yellow coloured in three dogs $(50.00 \%)$. On day 20, reddish urine was observed in five dogs $(83.33 \%)$ while in remaining one dog yellow coloured urine was recorded (16.67\%). Among the dogs studied for turbidity of urine on day (' 0 ') and 10 under Group 1B, four dogs $(66.67 \%)$ were having turbid urine and clear urine in a $\operatorname{dog}(33.33 \%)$, while on day 20 the turbidity of urine was observed in two dogs $(33.33 \%)$ and four dogs $(66.76 \%)$ in dogs.

The dogs having cystitis under Group 1C, macroscopic physical examination of seventeen urine samples on day 0 revealed dark reddish urine in twelve dogs $(70.59 \%)$ and yellow coloured in five cases $(29.41 \%)$. On day 10reddish urine was observed in two dogs $(11.76 \%)$ and yellow urine in fifteen dogs $(88.24 \%)$. On day 20 in all dogs (100 $\%$ ) yellow colour normal urine observed. Among the dogs studied for turbidity of urine on day (' 0 ') under Group 1C, thirteen dogs $(76.47 \%)$ were having turbid urine and clear urine in four dogs $(23.53 \%)$, while on day 10 the turbidity of urine was observed in five dogs $(29.41 \%)$ and in twelve dogs $(70.59 \%)$ 
had clear urine. On day 20, all dogs (100\%) had clear urine observed.

The dogs having mass in urinary bladder under Group 1C, macroscopic physical examination of eight urine samples revealed dark red urine in all cases $(100 \%)$ on day $\left({ }^{\prime} 0\right.$ '), while on day 10 dark red urine in three dogs $(37.50 \%)$ and yellow urine in five dogs $(62.50 \%)$ observed. On day 20 reddish urine in one $\operatorname{dog}(12.50 \%)$ and in seven dogs $(87.50 \%)$ yellow urine observed. Among the dogs studied for turbidity of urine on day (' 0 ') under Group 1C, turbidity observed in all cases $(100 \%)$ while on day 10 day turbidity and clear urine observed in four cases $(50.00$ $\%$, each). On day 20 clear urine were observed in all dogs $(100 \%)$.

The dogs having urolithiasis and subjected to surgical management under Group 2, macroscopic examination of eleven urine samples revealed on day (' 0 ') dark reddish urine in five dogs $(45.45 \%)$, reddish urine in four dogs $(36.36 \%)$ and yellow urine in two dogs $(18.18 \%)$. On day 10 and day 20 all dogs $(100 \%)$ show yellow urine. Among the dogs studied for turbidity of urine on day 0 under Group 2, turbidity observed in nine dogs $(81.82 \%)$ and clear urine in two cases $(18.18 \%)$, while on day 10 and 20 urine clear urine observed in all dogs $(100 \%)$.

The dogs having urolithiasis which were failed to respond medicinal management were subjected to surgical management under Group 3, six urine samples revealed on day (' 0 ') dark red urine in two dogs $(33.33 \%)$ and yellow urine in four dogs $(66.67 \%)$, while on day 10 and 20 yellow urine observed in all cases $(100 \%)$. Among the dogs studied for turbidity of urine on day (' 0 '), both turbid and clear urine were observed in three dogs $(50.00$ $\%$; each). On day 10 turbid urine in four dogs $(66.67 \%)$ and clear urine in two dogs (33.33 $\%)$ observed while on day 20 turbid urine in one $\operatorname{dog}(16.67 \%)$ and clear urine in five dogs $(83.33 \%)$ observed.

The changes in colour from dark reddish to normal yellow and reduction in turbidity from day (' 0 ') to day 10 and 20 after treatment are indicative of positive response to the treatment in the form of arrested haematuria. Almost similar findings to the observations of the present study are reported by Rajathi et al., (2006) and Gupta (2014) in dogs affected with cystitis, urolithiasis and polyp in urinary bladder. Pandurangrao (2017) reported reddish to dark red urine in 35.00 per cent dogs, pale to dark yellow in 20.00 per cent and normal in 20.00 per cent dogs suffering from urolithiasis. The stones with irregular shape elicit abrasive injuries to the smooth mucous membrane of the bladder and urethra resulting in to cystitis and urethritis.

\section{Microscopic examinations of urine}

The microscopic examination of urine samples of dogs $(n=29)$ having urolithiasis (Groups 1A,1B, 2, 3) in the present study revealed absence of crystals in 68.97 per cent (20) cases, whereas presence of struvite (Fig 1 ) and calcium oxalate crystals (Fig 2) were recorded in 27.58 (08) and 3.44 (1) case, respectively. Comparatively lower findings to the present observations were reported by Mircean et al., (2006) and Sran(2010) who reported no crystals $(50.00 \%)$ and calcium oxalate crystals (16.67) in dogs. However, Houston and Eaglesome (1999), Taskende (2015) reported comparatively higher struvite crystals followed by calcium oxalate in dogs suffering from urolithiasis. Pandurangrao (2017) found the presence of struvite crystals $(30.00 \%)$ in dogs followed by calcium oxalate crystals $(20.00 \%)$ and negative for crystals (20.00\%).

The microscopic examination of urine samples from the dogs $(n=17)$ having cystitis 
(Group 1C) revealed presence of leucocytes and intact RBCs in all the samples (Fig 3), however in some samples epithelial cells were noticed. The present findings are supported by the observations of Cetin et al., (2003) in dogs having urinary tract infections with presence leukocytes, erythrocytes, epithelial cells, squamous epithelial cells, epithelial casts and leukocytic casts. However, Kandula et al., (2017) reported presence of pus cells, erythrocytes and absence of crystalluria in dogs having cystitis. Roopali et al., (2018) carried microscopic examination of urine from dogs having urinary tract infection which revealed presence pus cells.

\section{Multistrip urinalysis}

The multistrip examination of urine samples from various group revealed the mean $\mathrm{RBC} / \mathrm{hpf}$, urine bilirubin, urobilinogen, urine ketones, urine glucose, and nitrite, WBC/hpf found to be varying non-significantly in all groups. However, a significant reduction in $\mathrm{RBC} / \mathrm{hpf}$ in the urine samples was noted in dogs having cystitis and neoplasia covered under Group 1C as well as in the dogs (Group 2) subjected to surgical management (Table 4). The mean urine protein $(\mathrm{mg} / \mathrm{dl})$ levels varied non-significantly, except the in the dogs under Group 1C having cystitis and Group 2 dogs subjected for surgical management with significant reduction in protein levels in urine (Table 5). The mean WBC/hpf found to be varying nonsignificantly in the dogs with urolithiasis during course of therapeutic management. However, a significant reduction in WBC/hpf in the urine samples was noted in dogs having cystitis covered under Group $\mathrm{C}$ as well as in the dogs (Group 2) subjected to surgical management (Table 6). The findings of the present study are in agreement with the findings of Rajathi et al., (2006), Brunet al., (2008), Gupta (2014) and Pandurangrao (2017). Colakoglu et al., (2017) reported comparatively higher mean urine specific gravity $(1.024 \pm 0.001)$ in dogs having lower urinary tract infection as compared to the present findings of dogs having cystitis.

The mean urine $\mathrm{pH}$ levels recorded for the dogs under Groups 1B, 1C, 2 and 3 varied non-significantly from $6.08 \pm 0.22$ to $7.45 \pm 0.16$, except the in the dogs (Group 1A) having urolithiasis had highly alkaline $\mathrm{pH}$ of urine to be $7.64 \pm 0.09$ on day ('0'), which reduced to $6.91 \pm 0.12$ and again increase to $7.34 \pm 0.23$ significantly on day 10 and 20 during the course of treatment with medicinal dissolution using Ammonium Chloride (Table 7). The change observed in the $\mathrm{pH}$ of urine of dogs under Group 1A indicated favourable response to the medicinal management of urolithiasis using Ammonium Chloride in dogs having alkaline $\mathrm{pH}$. The present findings are in accordance with the observations reported by Sancak et al., (2009). Urine pH plays an important role in formation of uroliths as opined by Parrah et al., (2013). Cetin et al., (2003) analysed 100 urine samples from dogs having symptoms of UTI and reported the urine $\mathrm{pH}$ to be between 6 to 9.

\section{References}

Brun, M.V., Oliveira, S.T., Messina, S.A., Stedile, R. and Oliveira, R.P. (2008). Laparoscopic cystotomy for urolith removal in dogs: three case reports. Arquivo Brasileiro de MedicinaVeterinária e Zootecnia, 60(1): 103-108.

Caswell, M. (2011). Transitional cell carcinoma of the urinary bladder in a 14-year-old dog. Canadian Veterinary Journal, 52: 673-675.

Cetin, C., Senturk, S., Kocabiyik, A. L., Temizel, M andOzel, E. (2003). Bacteriological Examination of Urine Samples from Dogs with Symptoms of 
Urinary Tract Infection. Turkish Journal of Veterinary and Animal Sciences, 27: 1225-1229.

Colakoglu, E. C., Haydardedeoglu, A. E., Alihosseini, H. andHayirli, A. (2017). Efficacy of single-dose ceftriaxone versus multiple-dose enrofloxacin in dogs with uncomplicated lower urinary tract infection: a randomised clinical trial. VeterinarniMedicina, 62(03): 125130.

Gohil, K. M. (2016). Studies on incidence, diagnosis and management of surgical affections of urinary system in dogs. (M.V.Sc. Thesis, Anand Agricultural University, Anand).

Gupta, D. (2014). Diagnosis and Management of lower urinary tract disorders in female dogs. (M.V.Sc. Thesis, NanajiDeshmukh Veterinary Science University, Jabalpur, Madhya Pradesh).

Houston, D. M. and Eaglesome, H. (1999). Unusual case of foreign body-induced struvite urolithiasis in a dog. Canadian Veterinary Journal, 40: 125-126.

Kamble, M. V., Kale, V. D. andRaut, S. U. (2011). Urethral Calculi in a Dog and its Surgical Management. IntasPolivet, 12(II): 369-371.

Kandula, S., Karlapudi, S. K. andNagaraj, P. (2017). Cultural studies of urine from cystitis dogs. The Pharma Innovation Journal, 6(8): 247-250.

Madhu, D. N., Remya, V., Rohit Kumar, Sivanarayanan, T. B., Amarpal, Aithal, H. P., Kinjavdekar, P., Pawde, A. M. and Zama, M.M.S. (2013). Surgical Management of Obstructive Urolithiasis in a Dog. Indian Journal of Canine Practice, 5(1): 162-164.

Manjunatha, D. R., Anilkumar, M. C., Nagaraja, N., Girish, B. C., Basavaraj, B. andVasanth, M. S. (2016). Surgical management of urinary bladder leiomyosarcoma in a dog. Indian
Journal of Canine Practice, 8(1): 55-57. Mircean M., G. Giurgiu, VioricaMirceanandKatsaros K. (2006). Epidemiologic, Clinic and Ethiopathogenic studies in canine urolith. Buletin USAMV-CN, 63, 337342.

Mukherjee, P., Chakrabarti, A., Har, T., Batabyal, K. \& Das, B. (2014). Study of haematological profiles of dogs infected with pathogenic aerobes. Exploratory Animal and Medical Research, 4(1): 8185.

Pal (2015). Clinical studies on surgical management of canine urolithiasis. (M.V.Sc. Thesis, Anand Agricultural University, Anand).

Pandurangrao, B. A. (2017). Surgical management of urinary calculi by using different urethral approaches in dog. (M.V.Sc. Thesis, Maharashtra Animal and Fishery Sciences University, Nagpur).

Parrah, J. D., Moulvi, B. A., Gazi, M. A., Makhdoomi, D. M., Athar, H., Din, M. U., Dar, S. and Mir, A. Q. (2013). Importance of urinalysis in veterinary practice - A review. Veterinary World, 6(9): 640-646.

Rajathi, S., Ramani, C., Nagarajan, L., Sureshkumar, R. andAmeerjan, K. (2006). Urolithiasis in dogs: clinical, biochemical and haematological evaluation. Indian Journal of Veterinary Surgery, 27(2): 128.

Roopali, B., Roy, M. and Roy, S. (2018). Haemato-biochemical changes and therapeutic management of urinary tract infection in canines. The Pharma Innovation Journal, 7(6): 89-92.

Saharan, S., Chandratre, G., Mathew, R. V., Arora, N. and Vishal (2019).Surgical management of urinary bladder leiomyoma in a female dog. Indian Journal of Veterinary Surgery, 40(1): 73. 
Sahoo, M., Nath, I. and Singh, J. (2016). Urolithiasis with unusual complicagtion of lodged catheter in the bladder of spitz dog. Indian Journal of Canine Practice, 8(1): 41-43.

Sancak, I. G., Sancak, A. A. andOzgencil, F. E. (2009). SubmucosalUroliths in the VesicaUrinaria of a Male Dalmatian Dog. Turkish Journal of Veterinary and Animal Sciences, 33(1): 85-87.

Sarma. B. K. andKalita, D. (2019). Changes of haematological and biochemical parameters of canine having urinary system disorders. International Journal of Chemical Studies, 7(1): 501-504.

Shah, M. A., Bhat, A., Basha, M. A. andSaxena, A. (2018). Surgical Management of Urolithiasis in Male Dogs: A Clinical Review of 10 Cases. Indian Journal of Veterinary Science and Biotechnology, 13(3): 75-78.

Sharma, A K, Mogha, I. V., Singh, G. R., Amarpal andAithal, H. P. (2005). Haematobiochemical changes in cases of obstructive urolithiasis in dogs. Indian Journal of Veterinary Surgery, 26(1): 65-66.
Singh, P., Chawla, S. K., Chander, Chander, S., Singh, K., S., Behl, S.M. andChandolia, R.K. (2012). Ultrasonographic and radiographic observations in cases of obstructive urolithiasis in dogs. Indian Journal of Veterinary Surgery, 33(1): 45-46.

Singh, P., Chawla, S. K., Chander, S., Behl, S.M., Chandolia, R.K. andTayal, R. (2013). Obstructive Urolithiasis in Canine- Ultrasonographic and Radiographic Observations, International Journal of Molecular Veterinary Research, 3(4): 9-12.

Sran, S. S. (2010). Studies on dissolution protocols and surgical management of canine urolithiasis. (M.V.Sc. Thesis, Guru AngadDev Veterinary and Animal Sciences University, Ludhiana).

Taskande, P. E. (2015). Clinical studies on bovine and canine urolithiasis with special reference to dissolution protocol in dogs. (M.V.Sc. Thesis, Guru AngadDev Veterinary and Animal Sciences University, Ludhiana).

\section{How to cite this article:}

Parmar, J. J., P. V. Parikh, P. B. Dabhi, A. S. Parmar and KavitaKurup. 2021. Physiological, Hemato-biochemical and Urine Parameters Alterations in Lower Urinary Tract Affections in Dogs under Various Therapeutics Management. Int.J.Curr.Microbiol.App.Sci. 10(01): 24272438. doi: https://doi.org/10.20546/ijcmas.2021.1001.281 